Sri Lanka J. Aquat. Sci. 21 (2) (2016): 113-124

\title{
Impaired growth and erythrocyte nuclear lesions of immature Oreochromis niloticus exposed to waterborne crude oil: Persistent responses
}

\author{
S.H.N.P. Gunawickrama ${ }^{1}$, P.D.S.M. Panawala ${ }^{2}$, K.B.S. Gunawickrama ${ }^{2 *}$ \\ ${ }^{1}$ General Sir John Kotelawala Defence University, Kandawala Road, \\ Ratmalana 10380, Sri Lanka \\ ${ }^{2}$ Department of Zoology, Faculty of Science, University of Ruhuna, Matara \\ 81000, Sri Lanka \\ *Corresponding author (suneetha@zoo.ruh.ac.lk)
}

\begin{abstract}
Crude oil impact studies have largely been limited to marine setting and it hampers the understanding and predictability pertaining to freshwater environments following contamination episodes. Growth and erythrocyte nuclear abnormalities (ENA) were followed in freshwater fish Oreochromis niloticus experimentally exposed to crude oil (Arabian light) dispersed in water. Study comprised of a control (no crude oil in water), and two experimental groups with $5 \mu \mathrm{L} / \mathrm{L}$ and 25 $\mu \mathrm{L} / \mathrm{L}$ crude oil dispersed in water ( $5 \mathrm{ppm}$ and $25 \mathrm{ppm}$ respectively), and involved continuous exposure of fish (35 fish/tank in triplicate) with static renewal over a 90day period. Growth was estimated serially at 18 -day intervals $(n=40-60)$. Both exposure groups reduced $(\mathrm{p}<0.05)$ weight-based and length-based growth rates and specific growth rates. Giemsa-stained peripheral blood and head kidney smears on day $90(n=6)$ showed increased $(\mathrm{p}<0.05)$ micronuclei, nuclear buds, fragmented apoptotic nuclei and other types of ENA frequencies (per 1000 RBC) in the fish exposed to $25 \mathrm{ppm}$ crude oil. Moreover, crude oil induced ENA levels were quantitatively different $(p<0.05)$ between the peripheral blood and head kidney. Results show that crude oil hampers growth and sustains elevated ENA of $O$. niloticus juveniles in freshwater environment.
\end{abstract}

Keywords: Aquatic pollution; chronic toxicity; ENA; fish growth; head-kidney erythrocytes.

\section{Introduction}

Crude oil contamination adversely affects health of aquatic ecosystems. It is known that few millions of tonnes of crude oil enter maritime environment each year due to events such as natural seepages, tanker accidents and production water discharge at oil rigs. Contamination spreads to sediment and marine biota, and may drift into 
inland waters as oil spills reach subtidal zones, intertidal areas and further into estuaries (Lee and Page 1997; Sammarco et al. 2013; Fry and Anderson 2014). Rivers and connected lakes remain vulnerable when crude oil mining or transportation takes place in river basins (Kochhann et al. 2015), while any other freshwater systems may be at risk because of accidental leakage or spills owing to human error.

Crude oil spills in aquatic environments often kill organisms en masse by entrapment in the slick and due to acute toxicity. Nevertheless, the damage on survivors and those that undergo contamination away from the slick may not be apparent. Although investigations that followed oil spills over years are seen in the field setting (Thomas et al. 1999; Irvine et al. 2006; Roberts et al. 2006; Sammarco et al. 2013), laboratory verification of long-term responses continues to be necessary for proper prediction of the aftermath. Controlled experiments remain important in this regard, as it allows results to be attributed to the exposure unambiguously excluding confounding effects of field heterogeneity.

The chemical composition of crude oil is complex and oil field-dependent while the impact assessment on constituent basis remains arduous. However, the whole crude as a toxicant mixture will depict a more realistic picture. Crude oil effects on teleosts span from cytochromes P450 gene induction (Carls et al. 2005; Brewton et al. 2013), oxidative stress (Roberts et al. 2006) and genotoxicity (Harvey et al. 1999; Pietrapiana et al. 2002) to growth retardation (Brewton et al. 2013), reproduction failure (Brannon et al. 2012) and teratogenicity (Heintz et al. 1999; Incardona et al. 2013). In addition, erythrocyte nuclear abnormalities (ENA) have been reported in finfish exposed to crude oil (Barsiene et al. 2006). Micronuclei and most ENA types contain cytoplasmic chromosome fragments or intact chromosomes that failed in proper segregation during mitotic cell division (Udroiu 2006). The increased ENA frequencies are symptomatic to genotoxicity and suggest exposure to genotoxic compounds (Çavaş and Ergene-Gözükara 2005).

Present study focuses on whether waterborne crude oil compromises growth, and genetic integrity measured as ENA in juvenile Oreochromis niloticus. The results will be valuable in assessing long-term crude oil impact scenario in freshwater environments.

\section{Materials and Methods}

Oreochromis niloticus fingerlings were obtained from the Fish Breeding Centre, Udawalawe, Sri Lanka. Following transportation, fish were acclimatized for two weeks in the laboratory experimental setup of identical fiberglass tanks containing $130 \mathrm{~L}$ of aged municipal water with moderate aeration each. Triplicated setup included two treatments of crude oil (Arabian Light, Ceylon Petroleum Corporation) with $5 \mu \mathrm{L} / \mathrm{L}$ and $25 \mu \mathrm{L} / \mathrm{L}$ crude oil dispersed manually in water (5 ppm and $25 \mathrm{ppm}$ (volume/volume) respectively), and a control (no crude oil). A number of 35 fish were assigned randomly into each of the nine tanks. Continuous exposure level and water quality were maintained by complete renewal of the experimental setup on each successive fourth day. Dissolved Oxygen, temperature, 
$\mathrm{pH}$ and salinity were monitored on the third day from each renewal. Fish were fed throughout the study with formulated Prima Floating Foods $®$ (Ceylon Aquatech Private Ltd, Sri Lanka) adjusted at $2 \%$ body weight (w/w) once a day.

Weight and length measurements were obtained from 20 random fish from each tank and serially with 18-day intervals over 90 days. On day 90, peripheral blood was drawn from the caudal vein of fish under anesthesia with benzocaine, and microscopic smears were prepared and stained in $10 \%$ Giemsa as described by Barsiene et al. (2006) before mounting in DPX medium. Pieces of head kidney (cephalic kidney) dissected out from fish were used to make a blood smear by pulling it gently on glass slide before staining and mounting in the same manner. Both peripheral blood and cephalic kidney mounts were observed under oilimmersion in a bright-field light microscope at 10x100 for enumeration of four categories of ENA, i.e. micronuclei, nuclear buds, fragmented nuclei and other altered nuclear morphologies (including blebbed, lobed, notched nuclei and binucleated RBC) as shown by da Silva Souza and Fontanetti (2006). Blind counts were taken up to a total of 5,000 erythrocytes per fish by the same observer.

Growth indices were estimated according to Hopkins (1992), and length growth rate $(\mathrm{mm} /$ day) and weight growth rate (g/day) were estimated for intervals between day one and respective sampling time points. Specific growth rates (SGR) of weight and length were calculated for 90-day experimental duration using SGR $=100\left(\ln \mathrm{W}_{2}-\ln \mathrm{W}_{1}\right) /\left(\mathrm{t}_{2}-\mathrm{t}_{1}\right)$ and $\mathrm{SGR}_{\mathrm{L}}=100\left(\ln \mathrm{L}_{2}-\ln \mathrm{L}_{1}\right) /\left(\mathrm{t}_{2}-\mathrm{t}_{1}\right)$ respectively where 2 and 1 represent final and initial status at times $t_{2}$ and $t_{1}$.

Statistical analyses were performed using STATISTICA 7 software. Growth indices were tested by one way ANOVA among the groups within sampling timepoints. ENA among experimental groups, and ENA between peripheral blood and cephalic kidney within groups were compared by non-parametric Kruskal Wallis and Mann-Whitney U tests respectively.

\section{Results}

Water quality was within the stated ranges across the tanks at monitoring time points throughout 90-day duration; temperature $28.2-28.3^{\circ} \mathrm{C}, \mathrm{pH}$ 6.6-6.9, salinity 0.13-0.14 g/L and dissolved oxygen 3.36-3.43 mg/L. Both pre-exposure length and weight remained similar ( $>0.05)$ among all groups (Table 1) and subsequently showed an increasing tendency over the duration. However, as compared to control, waterborne crude oil affected $(\mathrm{p}<0.05)$ total length as well as total weight since day 36 . Fish showed reduced length- and weight-based growth rates $(\mathrm{p}<0.05)$ in $5 \mathrm{ppm}$ and 25ppm groups (Table 2). Similarly, specific growth rates estimated for weight and length changes over 90 day period were lower in both exposed groups as compared to respective control (Table 3). 
Table 1. Length (L, mm) and weight (W, g) of Oreochromis niloticus exposed to crude oil (mean \pm SD; $\mathrm{n}=40-60$ )

\begin{tabular}{ccrrrl}
\hline day & & Control & 5 ppm crude oil & $25 p p m$ crude oil & \\
\hline 1 & W & $7.68 \pm 2.66^{\mathrm{a}}$ & $8.43 \pm 2.82^{\mathrm{a}}$ & $8.16 \pm 2.78^{\mathrm{a}}$ & \\
& $\mathrm{L}$ & $75.95 \pm 8.93^{\mathrm{a}}$ & $77.82 \pm 9.93^{\mathrm{a}}$ & $77.82 \pm 8.63^{\mathrm{a}}$ & \\
18 & $\mathrm{~W}$ & $10.18 \pm 2.73^{\mathrm{a}}$ & $9.14 \pm 3.34^{\mathrm{a}}$ & $8.98 \pm 2.72^{\mathrm{a}}$ & \\
& $\mathrm{L}$ & $82.40 \pm 9.85^{\mathrm{a}}$ & $83.66 \pm 10.11^{\mathrm{a}}$ & $78.89 \pm 9.99^{\mathrm{b}}$ & $*$ \\
36 & $\mathrm{~W}$ & $11.32 \pm 3.49^{\mathrm{a}}$ & $9.67 \pm 3.74^{\mathrm{b}}$ & $9.42 \pm 2.93^{\mathrm{b}}$ & $*$ \\
& $\mathrm{~L}$ & $88.08 \pm 9.72^{\mathrm{a}}$ & $83.25 \pm 11.29^{\mathrm{b}}$ & $80.61 \pm 10.58^{\mathrm{b}}$ & $* *$ \\
54 & $\mathrm{~W}$ & $14.45 \pm 3.87^{\mathrm{a}}$ & $12.50 \pm 4.29^{\mathrm{b}}$ & $12.36 \pm 4.34^{\mathrm{b}}$ & $*$ \\
& $\mathrm{~L}$ & $97.18 \pm 8.95^{\mathrm{a}}$ & $92.23 \pm 10.40^{\mathrm{b}}$ & $90.69 \pm 11.06^{\mathrm{b}}$ & $*$ \\
75 & $\mathrm{~W}$ & $16.34 \pm 3.92^{\mathrm{a}}$ & $13.52 \pm 3.67^{\mathrm{b}}$ & $12.81 \pm 4.77^{\mathrm{b}}$ & $*$ \\
& $\mathrm{~L}$ & $102.41 \pm 8.60^{\mathrm{a}}$ & $96.49 \pm 9.69^{\mathrm{b}}$ & $92.69 \pm 11.96^{\mathrm{b}}$ & $* *$ \\
90 & $\mathrm{~W}$ & $18.73 \pm 3.73^{\mathrm{a}}$ & $14.64 \pm 4.94^{\mathrm{b}}$ & $14.53 \pm 4.45^{\mathrm{b}}$ & $* *$ \\
& $\mathrm{~L}$ & $107.46 \pm 6.55^{\mathrm{a}}$ & $99.97 \pm 11.66^{\mathrm{b}}$ & $101.79 \pm 9.67^{\mathrm{b}}$ & $* *$ \\
\hline
\end{tabular}

$* \mathrm{p}<0.05, \quad * * \mathrm{p}<0.001$, one-way ANOVA followed by Tukey HSD where dissimilar superscripts indicate statistical significance among groups at a given sampling day

Table 2. Growth rates of Oreochromis niloticus exposed to waterborne crude oil.

\begin{tabular}{rlccrl}
\hline day & & Control & 5ppm crude oil & $25 p p m$ crude oil & \\
\hline 18 & WGR & $0.138 \pm 0.033^{\mathrm{a}}$ & $0.039 \pm 0.025^{\mathrm{b}}$ & $0.045 \pm 0.006^{\mathrm{b}}$ & $*$ \\
& LGR & $0.358 \pm 0.022^{\mathrm{a}}$ & $0.321 \pm 0.071^{\mathrm{b}}$ & $0.059 \pm 0.005^{\mathrm{c}}$ & $* *$ \\
36 & WGR & $0.101 \pm 0.047^{\mathrm{a}}$ & $0.035 \pm 0.015^{\mathrm{b}}$ & $0.034 \pm 0.019^{\mathrm{b}}$ & $*$ \\
& LGR & $0.336 \pm 0.082^{\mathrm{a}}$ & $0.149 \pm 0.014^{\mathrm{ab}}$ & $0.077 \pm 0.014^{\mathrm{b}}$ & \\
54 & WGR & $0.129 \pm 0.023^{\mathrm{a}}$ & $0.075 \pm 0.009^{\mathrm{ab}}$ & $0.078 \pm 0.007^{\mathrm{b}}$ & $*$ \\
& LGR & $0.394 \pm 0.068^{\mathrm{a}}$ & $0.264 \pm 0.043^{\mathrm{ab}}$ & $0.239 \pm 0.048^{\mathrm{b}}$ & \\
75 & WGR & $0.118 \pm 0.019^{\mathrm{a}}$ & $0.068 \pm 0.017^{\mathrm{b}}$ & $0.061 \pm 0.016^{\mathrm{b}}$ & $*$ \\
& LGR & $0.353 \pm 0.041^{\mathrm{a}}$ & $0.247 \pm 0.061^{\mathrm{ab}}$ & $0.197 \pm 0.057^{\mathrm{b}}$ & \\
90 & WGR & $0.125 \pm 0.016^{\mathrm{a}}$ & $0.072 \pm 0.019^{\mathrm{b}}$ & $0.067 \pm 0.003^{\mathrm{b}}$ & $*$ \\
& LGR & $0.350 \pm 0.027^{\mathrm{a}}$ & $0.244 \pm 0.048^{\mathrm{b}}$ & $0.245 \pm 0.006^{\mathrm{b}}$ & \\
\hline
\end{tabular}

WGR $=$ weight growth rate $(\mathrm{g} /$ day $), \mathrm{LGR}=$ length growth rate $(\mathrm{mm} /$ day $)$, mean \pm $\mathrm{SD}(\mathrm{n}=40-60)$ compared to day one;

${ }^{*} \mathrm{p}<0.05, * * \mathrm{p}<0.001$ one-way ANOVA followed by Tukey HSD where dissimilar superscripts indicate significant difference among groups at a given sampling day. 
S.H.N.P. Gunawickrama et al./Sri Lanka J. Aquat. Sci. 21(2) (2016): 113-124

Table 3. Specific growth rates of Oreochromis niloticus exposed to crude oil.

\begin{tabular}{lcccc}
\hline & Control & 5ppm crude oil & \multicolumn{2}{c}{$25 p p m$ crude oil } \\
\hline Weight based $^{x}$ & $1.061 \pm 0.165^{\mathrm{a}}$ & $0.673 \pm 0.187^{\mathrm{b}}$ & $0.573 \pm 0.165^{\mathrm{b}}$ & $*$ \\
Length based $^{y}$ & $0.391 \pm 0.039^{\mathrm{a}}$ & $0.278 \pm 0.057^{\mathrm{b}}$ & $0.273 \pm 0.008^{\mathrm{b}}$ & $*$ \\
\hline
\end{tabular}

${ }^{x} \mathrm{SGRW}=100\left(\ln \mathrm{W}_{2}-\ln \mathrm{W}_{1}\right) /\left(\mathrm{t}_{2}-\mathrm{t}_{1}\right) ;{ }^{y} \mathrm{SGRL}=100\left(\ln \mathrm{L}_{2}-\ln \mathrm{L}_{1}\right) /\left(\mathrm{t}_{2}-\mathrm{t}_{1}\right) ;$ given as \% per day, over 90 days. ${ }^{*} \mathrm{p}<0.05$ one-way ANOVA followed by Tukey HSD where dissimilar superscripts indicate significant difference among groups; mean $\pm \mathrm{SD}$; $\mathrm{n}=40-60$

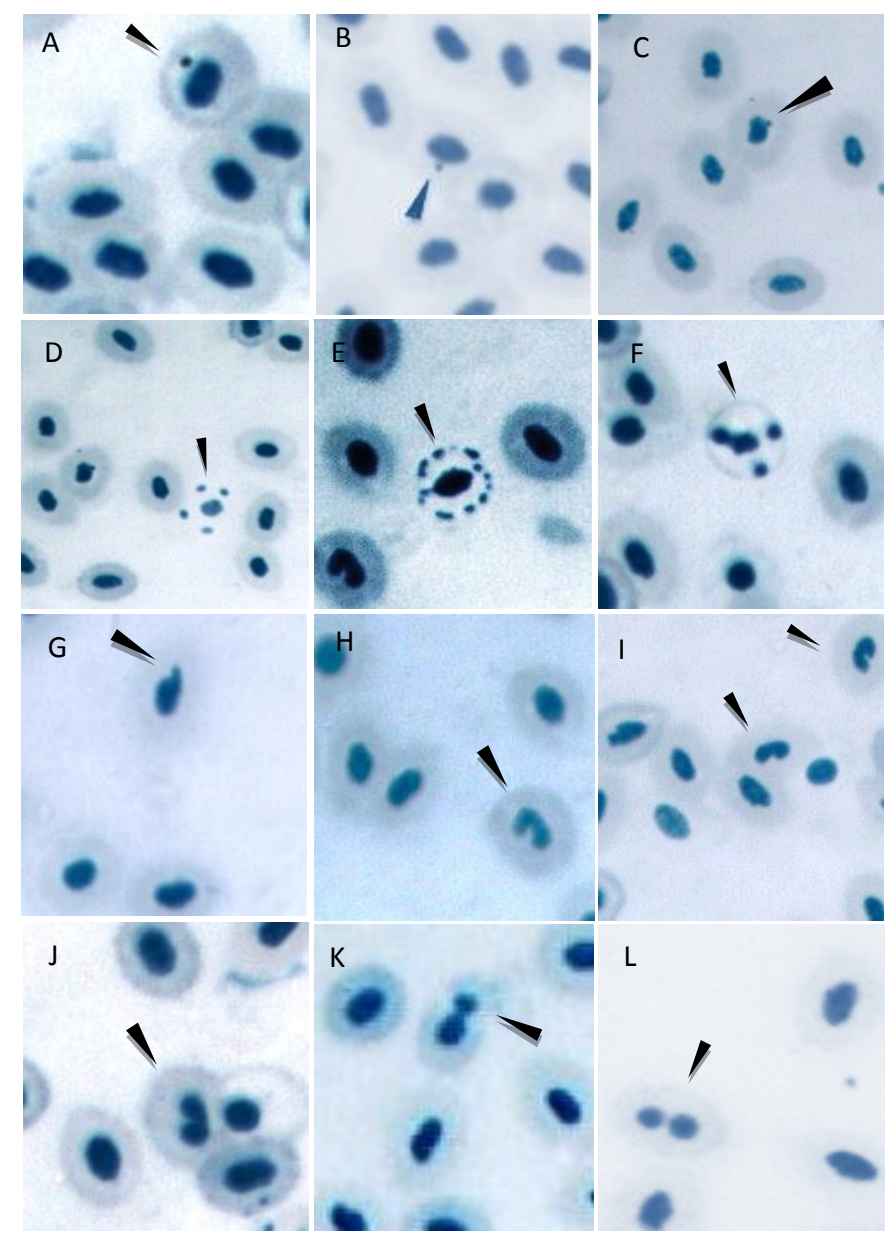

Figure 1. Erythrocyte nuclear abnormalities in peripheral blood of Oreochromis niloticus exposed to waterborne crude oil (arrows in A: micronuclei; B \& C: nuclear buds; D, E \& F: fragmented-apoptotic nuclei; and other altered nuclei including G: blebbed nuclei; H \& I: notched nuclei; J \& K: lobed nuclei, and L: binucleated RBC) (Images taken from Giemsa stained smears with 10x100 magnification and 510 fold appropriate digital enlargement). 

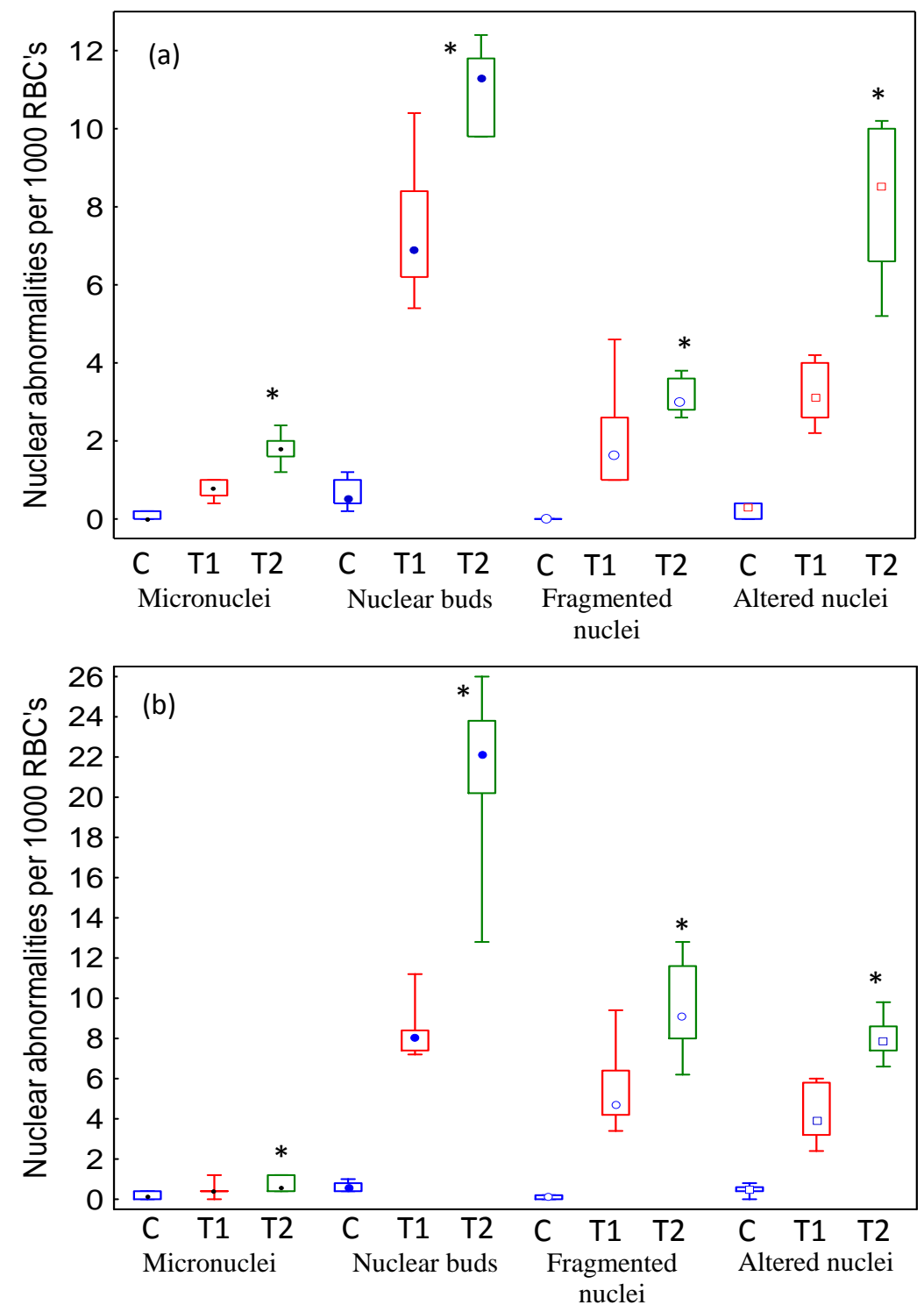

Figure 2. Erythrocyte nuclear abnormalities in (a) peripheral blood and (b) cephalic kidney of Oreochromis niloticus exposed to waterborne crude oil over 90 days (C: zero/control, T1 \& T2: 5 and 25 ppm crude oil respectively; Data $(\mathrm{n}=6)$ presented as median, 25th and 75th percentiles (box), and minimum and maximum (whiskers); *Kruskal-Wallis test yielded $\mathrm{p}<0.05$ only between control and $25 \mathrm{ppm}$ group).

Long term continuous and renewed exposure to $25 \mathrm{ppm}$ crude oil dispersed in water increased the frequency of all forms of erythrocyte nuclear abnormalities $(p<0.05)$ counted in the study namely, micronuclei, nuclear buds, fragmented nuclei 
and other types of abnormalities (hereafter referred to as altered nuclei, including blebbed, notched, lobed nuclei and binucleated cells; Figure 1) compared to control responses (Figure 2). The results show genotoxic impact of water borne crude oil on both peripheral blood and cephalic kidney erythrocytes. Fish exposed to 5 ppm crude oil did not however develop the abnormalities $(\mathrm{p}>0.05)$ at the same time point, day 90 .

Intra-group comparison between peripheral blood and cephalic kidney with Mann-Whitney U test suggested that compartmentalized differences could occur in development of crude-oil induced ENA. Cephalic kidney showed higher $(\mathrm{p}<0.05)$ nuclear buds, and fragmented nuclei levels in 5ppm, and both 5ppm \& 25ppm groups respectively. Control responses were not statistically different $(p>0.05)$ between the tissues. Micronuclei showed increased level in peripheral blood as compared to cephalic kidney in $25 \mathrm{ppm}$ group $(\mathrm{p}<0.05)$.

\section{Discussion}

This paper addresses the areas of finfish growth and cytogenetic toxicity in a model freshwater fish species upon continuous exposure to crude oil in water over 90 days. The results showed growth retardation with certainty as total length and total weight growth declined as early as day 36 in such a way that it persisted throughout the experiment. Weight growth rate (g/day) and length growth rate $(\mathrm{mm} /$ day) estimated for contiguous periods, and specific growth rates (\% per day) maintained by fish over entire experimental duration were affected as well. Comparable responses had been reported in other long-term experiments from both marine and freshwater finfishes previously. Those include weight reduction in juvenile pink salmon exposed 40 days to water soluble fraction (WSF) of crude oil (Moles and Rice 1983), reduced growth rate and survival of cutthroat trout exposed 90 days to crude oil (Woodward et al. 1981), and declined weight of Nile tilapia exposed to WSF over 10 weeks (Omoregie and Ufodike 2000). Decreased growth was also reported in polar cod fed with crude oil contaminated food (Christiansen and George 1995) and in larval Pacific herring exposed 16 days to weathered Alaskan crude oil (Carls et al. 1999). In feral pink salmon, embryonic stage exposure to weathered crude oil resulted in weight reduction following 200-300 days (Heintz et al. 2000). Brewton et al. (2013) reported growth reduction of spotted sea trout following $2010 \mathrm{BP} /$ Deep Water Horizon oil spill in northern Gulf of Mexico. It is notable that the growth was affected in juvenile Oreochromis niloticus similar to marine fish responses to prolonged crude oil exposure. Although the exact mechanism remains obscure, the compromised growth could be a result of hindered molecular processes in tilapia development. The energetic costs in withstanding oil impact and in biotransformation of oil components cannot be ruled out as well.

Genotoxicity of crude oil exposure on $O$. niloticus juveniles evident in terms of erythrocyte nuclear abnormalities (ENA) both in peripheral blood and cephalic kidney are notable. The observation remains consistent with the previous reports on the increased ENA frequencies in teleosts exposed to crude oil (Barsiene et al. 2006), WSF of diesel fuel (Vanzella et al. 2007) and crude oil constituents such as PAHs (Al-Sabti and Metcalfe 1995). The fragmented nuclei in the study are 
presumed to be apoptotic. Similarly, crude oil induced apoptotic red blood cells are known in experimental marine fish (Barsiene et al. 2006). It is plausible that ENA responses of tilapia in this study were persistent and sustained. The fish had been exposed continually over 90 days at the sampling point and it was unlikely that the ENA results were transient under such circumstances.

Statistically significant compartmentalized differences emerged in crude-oil induced ENA between peripheral blood and head kidney (HK) may show local influence on the responses. In tilapia, head kidney (pronephros) is a major site of hematopoiesis whereas the trunk kidney (mesonephros) functions primarily in excretion (Abdel-Aziz et al. 2010). The same authors maintain that head kidney accommodates various erythroblasts including young, mature as well as aging erythrocytes suggesting that it remains an active site of erythropoietic process. In this context, the differentiation and cell cycle activities such as DNA replication, chromatin condensation and nuclear formation as well as apoptosis may be commonplace in HK. In contrast, peripheral blood predominantly accommodates mature erythrocytes in circulation. Accordingly, toxicant induced compartmentalized ENA frequencies in HK may emerge different as compared to peripheral blood levels. Peripheral blood first encounters environmental toxicants across the gills and increased micronuclei frequencies evident in it is notable. Similar discrepancy of apoptosis induction in erythrocytes between $\mathrm{HK}$ and peripheral blood were reported in fish following three weeks of exposure to crude oil mixed with PAHs and alkylphenols (Barsiene et al. 2006), a toxic cocktail similar to produced water from oil platforms. ENA in teleosts are induced by unrelated agents such as laboratory genotoxicants (Ayllon and Garcia-Vazquez 2000, 2001), gamma radiation (Anbumani and Mohankumar 2012), heavy metals (Sanchez-Galan et al. 2001), polycyclic aromatic hydrocarbons (Oliveira et al. 2007), insecticides (Muranli and Güner 2011), petroleum refinery effluents (da Silva-Souza and Fontanetti 2006), and 17- $\beta$ estradiol (Teles et al. 2006). The diversity among inducers may suggest multiple pathways that perhaps converge and trigger ENA induction.

In conclusion, continuous exposure to crude oil causes growth retardation and sustains ENA induction in $O$. niloticus juveniles in freshwater environment. Results promote the importance of contamination-free practices pertaining to petroleumcrude industries. This is of particular importance that $O$. niloticus is a major constituent species in the inland fishery of Sri Lanka, which forms a cheap source of animal protein for rural communities (Amarasinghe 2002, 2013).

\section{Acknowledgements}

All laboratory facilities and transportation/field costs provided by Department of Zoology, Faculty of Science, University of Ruhuna, Sri Lanka are appreciated. Comments from an anonymous referee were helpful in improving the text. 


\section{References}

Abdel-Aziz E.S.H., T.E.S. Ali, S.B.S. Abdu \& H.F. Fouad 2010. Haemopoiesis in the head kidney of tilapia, Oreochromis niloticus (Teleostei: Cichlidae): a morphological (optical and ultrastructural) study. Fish Physiology and Biochemistry 36: 323-336. doi: 10.1007/s10695-008-9297-z

Al-Sabti K. \& C.D. Metcalfe 1995. Fish micronuclei for assessing genotoxicity in water. Mutation Research 343: 121-135.

Amarasinghe U.S. 2002. The Fishery and population dynamics of Oreochromis mossambicus and Oreochromis niloticus (Osteichthyes, Cichlidae) in a shallow irrigation reservoir in Sri Lanka. Asian Fisheries Science 15(1): 720.

Amarasinghe U.S. 2013. Fisheries resources in alleviation of hunger and malnutrition in Sri Lanka - accomplishment and challenges. Sri Lanka Journal of Aquatic Sciences 18: 1-15. doi: http://dx.doi.org/10.4038/sljas.v18i0.7034

Anbumani S. \& M.N. Mohankumar 2012. Gamma radiation induced micronuclei and erythrocyte cellular abnormalities in the fish Catla catla. Aquatic Toxicology 122-123: 125-132. doi: 10.1016/j.aquatox.2012.06.001

Ayllon F. \& E. Garcia-Vazquez 2000. Induction of micronuclei and other nuclear abnormalities in European minnow Phoxinus phoxinus and mollie Poecilia latipinna: an assessment of the fish micronucleus test. Mutation Research 467: 177-186. doi: 10.1016/S1383-5718(00)00033-4

Ayllon F. \& E. Garcia-Vazquez 2001. Micronuclei and other nuclear lesions as genotoxicity indicators in rainbow trout Oncorhynchus mykiss. Ecotoxicology and Environmental Safety 49: 221-225. doi: 10.1006/eesa.2001.2065

Barsiene J., V. Dedonyte, A. Rybakavas, A. Laura \& O.K. Andersen 2006. Investigation of micronuclei and other nuclear abnormalities in peripheral blood and kidney of marine fish treated with crude oil. Aquatic Toxicology 78S: S99-S104. doi: dx.doi.org/10.1016/j.aquatox.2006.02.022

Brannon E.L., K. Collins, M.A. Cronin, L.L. Moulton, A.L. Maki, K.R. Parker 2012. Review of the Exxon Valdez oil spill effects on pink salmon in Prince William Sound Alaska. Reviews in Fisheries Science 20: 20-60. doi: 10.1080/10641262.2011.643697

Brewton R.A., R. Fulford \& R.J. Griffitt 2013. Gene expression and growth as indicators of effects of the BP deepwater horizon oil spill on spotted sea trout (Cynoscion nebulosus). Journal of Toxicology and Environmental Health 76: 198-1209. doi: 10.1080/15287394.2013.848394.

Carls M.G., R.A. Heintz, G.D. Marty \& S.D. Rice 2005. Cytochrome P4501A induction in oil-exposed pink salmon Oncorhynchus gorbuscha embryos predicts reduced survival potential. Marine Ecology Progress Series 301: 253-265. doi: 10.3354/meps301253 
Carls M.G., S.D. Rice \& J.E. Hose. 1999. Sensitivity of fish embryos to weathered crude oil: Part I. Low-level exposure during incubation causes malformations, genetic damage, and mortality in larval Pacific herring (Clupea pallasi). Environmental Toxicology and Chemistry 18: 481-493. doi: 10.1002/etc.5620180317

Çavaş T. \& S. Ergene-Gözükara 2005. Induction of micronuclei and nuclear abnormalities in Oreochromis niloticus following exposure to petroleum refinery and chromium processing plant effluents. Aquatic Toxicology 74: 264-271. doi: 10.1016/j.aquatox.2005.06.001

Christiansen J.S. \& S.G. George 1995. Contamination of food by crude oil affects food selection and growth performance, but not appetite, in an Arctic fish, the polar cod (Boreogadus saida). Polar Biology 15: 277-281. doi: 10.1007/BF00239848

da Silva-Souza T. \& C.S. Fontanetti 2006. Micronucleus test and observation of nuclear alterations in erythrocytes of Nile tilapia exposed to waters affected by refinery effluent. Mutation Research 605: 87-93. doi: 10.1016/j.mrgentox.2006.02.010

Fry B. \& L.C. Anderson 2014. Minimal incorporation of Deepwater Horizon oil by estuarine filter feeders. Marine Pollution Bulletin 80: 282-287. doi: 10.1016/j.marpolbul.2013.10.018

Harvey J.S., B.P. Lyons, T.S. Page, C. Stewart \& J.M. Parry 1999. An assessment of the genotoxic impact of the Sea Empress oil spill by the measurement of DNA adduct levels in selected invertebrate and vertebrate species. Mutation Research 441: 103-114. doi: 10.1016/S1383-5718(99)00037-6

Heintz R.A., S.D. Rice, A.C. Wertheimer, R.F. Bradshaw, F.P. Thrower, J.E. Joyce \& J. W. Short 2000. Delayed effects on growth and marine survival of pink salmon Oncorhynchus gorbuscha after exposure to crude oil during embryonic development. Marine Ecology Progress Series 208: 205-216. doi: 10.3354/meps208205

Heintz R.A., J.W. Short \& S.D. Rice 1999. Sensitivity of fish embryos to weathered crude oil: Part II. Increased mortality of pink salmon (Oncorhynchus gorbuscha) embryos incubating downstream from weathered Exxon Valdez crude oil. Environmental Toxicology and Chemistry 18: 494-503. doi: 10.1002/etc.5620180318

Hopkins K.D. 1992. Reporting fish growth: A review of the basics. Journal of the World Aquaculture Society 23: 173-179. doi: 10.1111/j.17497345.1992.tb00766.x

Incardona J.P., T.L. Swart, R.C. Edmund, T.L. Linbo, A. Aquilina-Beck, C.A. Sloan, L.D. Gardner, B.A. Block \& N.L. Scholz 2013. Exxon Valdez to Deepwater Horizon: Comparable toxicity of both crude oils to fish early life stages. Aquatic Toxicology 142-143: 303-316. doi: 10.1016/j.aquatox.2013.08.011 
Irvine G.V., D.H. Mann \& J.W. Short 2006. Persistence of 10-year old Exxon Valdez oil on Gulf of Alaska beaches: The importance of boulder-armoring. Marine Pollution Bulletin 52: 1011-1022. doi: 10.1016/j.marpolbul.2006.01.005

Kochhann D., M.M. Jardim, F.X.V. Domingos \& A. LuisVal 2015. Biochemical and behavioral responses of the Amazonian fish Colossoma macropomum to crude oil: The effect of oil layer on water surface. Ecotoxicology and Environmental Safety 111: 32-41. doi: 10.1016/j.ecoenv.2014.09.016

Lee R.F. \& D.S. Page 1997. Petroleum hydrocarbons and their effects in subtidal regions after major oil spills. Marine Pollution Bulletin 34: 928-940. doi: 10.1016/S0025-326X(97)00078-7

Moles A. \& S.D. Rice 1983. Effects of crude oil and naphthalene on growth, caloric content, and fat content of pink salmon juveniles in seawater. Transactions of the American Fisheries Society 112: 205-211. doi: 10.1577/15488659(1983) 112<205:EOCOAN>2.0.CO;2

Muranli F.D.G. \& U. Güner 2011. Induction of micronuclei and nuclear abnormalities in erythrocytes of mosquito fish (Gambusia affinis) following exposure to the pyrethroid insecticide lambda-cyhalothrin. Mutation Research 726: 104-108. doi: 10.1016/j.mrgentox.2011.05.004

Oliveira M., M. Pacheco \& M.A. Santos 2007. Cytochrome P4501A, genotoxic and stress responses in golden grey mullet (Liza aurata) following short-term exposure to phenanthrene. Chemosphere 66: 1284-1291. doi: 10.1016/j.chemosphere.2006.07.024

Omoregie E. \& B.C. Ufodike 2000. Effects of water soluble fractions of crude oil on growth of the Nile tilapia, Oreochromis niloticus (L.). Bulletin of Environmental Contamination and Toxicology 64: 601-605. doi: 10.1007/s001280000045

Pietrapiana D., M. Moden, P. Guidetti, C. Falugi \& M. Vacchi 2002. Evaluating the genotoxic damage and hepatic tissue alterations in demersal fish species: a case study in the Ligurian Sea (NW-Mediterranean). Marine Pollution Bulletin 44: 238-243. doi: 10.1016/S0025-326X(01)00249-1

Roberts A.P., J.T. Oris \& W.A. Stubblefield 2006. Gene expression in caged juvenile coho salmon (Oncorhynchys kisutch) exposed to the waters of Prince William Sound, Alaska. Marine Pollution Bulletin 52: 1527-1532. doi: 10.1016/j.marpolbul.2006.05.016

Sammarco P.W., S.R. Kolian, R.A.F. Warby, J.L. Bouldin, W.A. Subra \& S.A. Porter 2013. Distribution and concentrations of petroleum hydrocarbons associated with the BP/ Deepwater Horizon oil spill, Gulf of Mexico. Marine Pollution Bulletin 73: 129-143. doi: 0.1016/j.marpolbul.2013.05.029

Sanchez-Galan S., A.R. Linde, F. Ayllon \& E. Garcia-Vazquez 2001. Induction of micronuclei in Eel (Anguilla anguilla L.) by heavy metals. Ecotoxicology and Environmental Safety 49: 139-143. doi: 10.1006/eesa.2001.2048

Teles M., M. Pacheco \& M.A. Santos 2006. Biotransformation, stress and genotoxic effects of $17 \beta$-estradiol in juvenile sea bass (Dicentrarchus labrax L.). Environment International 32: 470-477. doi: 10.1016/j.envint.2005.11.006 
Thomas R.E., C. Brodersen, M.G. Carls, M. Babcock \& S.D. Rice 1999. Lack of physiological responses to hydrocarbon accumulation by Mytilus trossulus after 3-4 years chronic exposure to spilled Exxon Valdez crude oil in Prince William Sound. Comparative Biochemistry and Physiology 122: 153-163. doi: $10.1016 / \mathrm{S} 0742-8413(98) 10099-3$

Udroiu I. 2006. The micronucleus test in piscine erythrocytes. Aquatic Toxicology 79: 201-204. doi: 10.1016/j.aquatox.2006.06.013

Vanzella T.P., C.B.R. Martinez \& I.M.S. Colus 2007. Genotoxic and mutagenic effects of diesel oil water soluble fraction on a neotropical fish species. Mutation Research 631: 36-43. doi: 10.1016/j.mrgentox.2007.04.004

Woodward D.F., P.M. Mehrle Jr \& W.L. Mauck 1981. Accumulation and sublethal effects of a Wyoming crude oil in cutthroat trout. Transactions of the American Fisheries Society 110: 437-445. doi: 10.1577/15488659(1981)110<437:AASEOA>2.0.CO;2 